\title{
Ways of introduction of the high-speed movement of passenger trains in Ukraine
}

\author{
Anna Shevchenko ${ }^{1, *}$, Oleksander Matviienko ${ }^{2}$, Vitalii Lyuty ${ }^{1}$, Vladimir Manuylenko ${ }^{1}$, \\ and Mykhailo Pavliuchenkov ${ }^{1}$ \\ ${ }^{1}$ Department of Track and Track Facilities, Ukrainian State University of Railway Transport, \\ Feierbakh Square 7, 61050, Kharkiv, Ukraine \\ ${ }^{2}$ Engineering systems "El-term". Vosstaniya Square 7/8, 61000 Kharkov. Ukraine
}

\begin{abstract}
The article describes the historical background of the introduction and development of high-speed traffic in the world. The main documents regulating the joint work of high-speed trains of the Commonwealth countries are considered. The main problems of highspeed traffic in Ukraine, and the railway as a whole are studied, analyzed, and described. Recommendations of the company SYSTRA, and the results of developments of Khargiprotrans JSC on the design, implementation and operation of high-speed highways in Ukraine are considered. In conclusion, the current state of the railways, the problems of the current track maintenance has been studied. For Ukraine, first of all, the fourth stage of construction which will connect Lviv with Kiev should be put into operation, based on the analysis of the passenger traffic of the State Committee of Statistics. In this direction, the roadbed and artificial structures are in satisfactory condition. The upper track structure of has sufficient strength. The effect of the profile on the speed of motion is compensated by the power of the locomotive.
\end{abstract}

\section{Introduction}

Mass transportation of goods and passengers is currently carried out by rail, road, air and water transport.

The formation of the transport market in Ukraine and the possibility of a free choice of means of transportation naturally causes competition between the above types of transport.

On foreign railways, competition for various modes of transport is assessed on the basis of the following factors [1]:

- delivery time of goods;

- frequency of departures;

- compliance with the traffic schedule;

- cost of cargo delivery;

\footnotetext{
${ }^{*}$ Corresponding author: Annshevc@gmail.com
} 
- ability to transport different goods;

- cost of transportation.

A serious competitor to rail transport is road transport, which has the following advantages:

- high speed of transportation;

- delivery of goods "from door to door";

- mobility;

- the possibility of delivery in small batches;

- lower costs for road infrastructure.

From statistical data it is known that the largest number of goods and passengers in our country is transported by rail.

Following the commissioning of high-speed railway which operated at a speed of $200 \mathrm{~km} / \mathrm{h}$ in Japan in 1964, in 1967 SNCI (French Railways) began a study of the creation of a railway network at a higher speed, namely, more than $250 \mathrm{~km} / \mathrm{h}$. The first results of this research appeared in 1970 and included the proposal to create a new line between Paris and Lyon. This proposal was based on the following three principles: a new line exclusively designed for passenger transportation, line compatibility with the existing network, operation based on high frequency of traffic, short journey duration. In 1986-1987, a plan was also developed in the Soviet Union to ensure the introduction of high-speed (up to $160 \mathrm{~km} / \mathrm{h}$ ) passenger trains on the main railways of the USSR by the leading railway universities [1-2].

For this purpose, on July 23, 1996, the European Community adopted Directive 96/48/EC on the Interoperability of the Trans-European High-Speed Railway Network. It should be noted that this directive combines the main technical characteristics of the infrastructure, rolling stock and operation of French highspeed technologies. This Directive was amended and supplemented in 2004 and then in 2007 by Directives 2004/50/EC and 2007/132/EC, which update its content in accordance with the 2001 Directive on the Interoperability of the Traditional Trans-European Railway System. This new impetus is part of the strategy for revitalizing rail transport in Europe and helping to cope with the harmful consequences associated with excessive use of road transport [3-6].

France is the first European country that introduced high-speed railways. The total length of the lines currently operating (2002) is 1.520 kilometres.

Thus, a unique high-speed line with a length of $1.070 \mathrm{~km}$ has been built from Calais to Marseilles with a train speed of $300 \mathrm{~km} / \mathrm{h}$ to create a link between the far north (tunnel under the English Channel) and the far south of France (Mediterranean Sea). The duration of the trip by the railroad system is a bit over 3 hours.

Considering that the geography of transport corridors is constantly changing due to many factors, the development of intercontinental communication along the main railway routes is constantly adjusted and improved.

\section{The basic part}

In the directives of the possibility of interaction of the trans-European high-speed railway network $[3,7]$, the main technical characteristics of the infrastructure, rolling stock and operation of French high-speed technology are combined, which are based on the following principles:

1. The new high-speed line is intended exclusively for passenger traffic.

2. High-speed line compatibility with the existing network. 
3. The operation is based on high frequency of movement and short duration of the trip.

The new line, intended for passenger transportations, together with the high capacity of the composition with respect to the mass speed allows rolling stock operation at steeper tilt angles [8,9]. The advantages of this option are listed below:

- a significant reduction in the cost of infrastructure by creating steeper slopes, reducing the number and size of necessary structures (tunnels, overpasses, etc.) and ensuring the most direct line laying. Thus, the length of new lines that will be built is reduced, and accordingly, the duration of trips is reduced.

- maximum utilization of the capacity of the new line by uniform distribution of the speed of the run of high-speed trains on new lines.

- providing a new line exclusively for the passenger movement. Due to this, the load on traditional railway lines in favor of freight traffic is substantially reduced and optimal operation of both types of railways is ensured, since the trains will run at approximately the same speeds.

Provided it is compatible with the existing railway network, the high-speed trains will be able to continue along existing routes and penetrate the city centers, thus creating extensive access to the new network throughout its territory. This is achieved through the following factors:

- $\quad$ penetration into the downtown area of cities by using existing lines, without the need to build an additional railway within the city, which would entail significant costs;

- no need to change trains at each end of the new line;

- gradual introduction and expansion of high-speed rail services.

Such an approach will help to reduce the cost of building a new line, expand the potential coverage of the territory and increase traffic. The rolling stock of the high-speed railway is fully compatible with the existing network, and will be able to continue on traditional railways at speeds acceptable for local lines. Thus, the high-speed railroads will be able to serve cities located several hundred kilometres from the new line. In countries that have different track widths on traditional and high-speed rail, new lines can be brought to existing stations by modifying the existing track width on station tracks. However, the decision to significantly cover the territory can be the manufacture of rolling stock, which automatically changes the width of the track, as it is in Spain and Japan [7].

High-speed compositions are light weight convoys with two locomotives and a high rated power that can be coupled. As a result, these compositions are capable of performing the following functions:

- to achieve a commercial operation speed of 300-350 km/h and a high average income rate in some regions of 250 to $300 \mathrm{~km} / \mathrm{h}$ (including the use of existing lines and stations). Such income speed significantly shortens the duration of trips, due to which absolutely competitive in comparison with air travel the duration of trips at distances of up to $1.500 \mathrm{~km}[9,10]$.

- run at high speed due to rapid turnover (design with two locomotives, which makes it possible to easily change the direction at the stations), despite the limited number of trains.

- to reach a full load in periods of maximum passenger turnover on new lines by creating a longer train by linking the two trains.

These principles have proven their reliability on high-speed rail in France. 
Based on the successful experience of operating a high-speed railway in France, other European countries, such as Germany and Italy, have developed their own railways. These national high-speed railways have various technical features and, in general, do not have the possibility of interaction. The European Community promotes the development of a trans-European network of high-speed railways. Therefore, it is necessary to guarantee the possibility of interaction between individual railways and their individual systems.

Proceeding from the tasks of creating a high-speed rail network, the total population and the economic situation in Ukraine, and also based on the basic principles of a high-speed railway, Ukraine proposes to create the following system of high-speed railways.

General information about Ukraine was analyzed in terms of geographical location, administrative regions, urban population and economic situation.

All the positive changes in the economy of Ukraine, the growth of the gross domestic product (as of August 2018 - the GDP of Ukraine is 2.9\% according to the World Bank), the activation of economic activity, the welfare and living standards of the population contribute to the increase in mobility and the volume of longdistance transportation over long distances.

In terms of population size, economic activity, cultural development, and tourism development, the following most important regions of Ukraine can be identified: Kiev and the Kiev region; Kharkiv and Poltava; Dnepropetrovsk, Dneprodzerzhinsk, Zaporozhye and Krivoy Rog; Region of Donbass (Donetsk, Lugansk, Mariupol, Gorlovka and Makeyevka); Odessa and Crimea peninsula (Odessa, Nikolaev, Kherson, Simferopol and Sevastopol); Western region (Lviv, Ternopil, Khmelnitsky and Vinnitsa) $[4,6]$.

Based on the experience of the networks of high-speed railways in Europe and in the world, the following tasks of creating a high-speed railway can be distinguished:

- the need for modern society is the creation of communication between cities, especially between large cities with economic, cultural and tourist potential;

- the movement of people: people always try to shorten the duration of travel as much as possible. The high-speed railway, a symbol of modern society, offers a fast, safe, convenient and efficient way of traveling with a high frequency of traffic, accessible to everyone;

- development of the country: high-speed railways do not harm the environment and are a safe mode of transport. They have a significant positive impact on economic activity (trade, tourism, hotel business, various services, etc.), urban development, real estate, employment, image of the country, etc. Thus, the highspeed railway greatly contributes to the development of the country.

Based on the successful experience of networks of world high-speed railways, the following main principles of their operation can be singled out: the lines are intended exclusively for passenger transportation; compatibility of the high-speed rail system with the existing rail network, as well as functioning based on the principles of high-frequency traffic and a competitive short duration of travel $[3,6$, 9].

Based on the tasks and basic principles of creating a network of high-speed railways (creating a communication between cities with a population of more than 300 thousand inhabitants, as well as constructing lines where possible on the most direct routes, the proposed high-speed lines are a long-term project for the future Table 1. 
The length of the proposed high-speed network is $3.071 \mathrm{~km}$.

The width of the track on the traditional railway of Ukraine differs from the standard gauge of the international network of transport corridors. The choice of the gauge width of $1520 \mathrm{~mm}$ (CIS) or $1435 \mathrm{~mm}$ (the international network of transport corridors standard) for use on the Ukrainian high-speed network is one of the most important issues of network implementation.

Thus, for the high-speed lines, three scenarios were developed: the use of the standard track gauge for the CIS countries $(1520 \mathrm{~mm})$, the use of the standard gauge of the international network of transport corridors $(1435 \mathrm{~mm})$, and the use of rolling stock adapted to both types of track (standard gauge of UIC for highspeed lines and standard gauge for traditional railways of the CIS countries, due to the variable width of wheel sets of rolling stock).

Table 1. Suggested routes for high-speed lines

\begin{tabular}{|c|c|c|c|c|}
\hline \multirow{2}{*}{\multicolumn{2}{|c|}{ Point of departure / arrival }} & \multicolumn{3}{|c|}{ Distance, $\mathbf{k m}$} \\
\hline & & \multirow{2}{*}{\begin{tabular}{|c|} 
Road \\
337 \\
\end{tabular}} & \multirow{2}{*}{$\begin{array}{c}\text { Railway } \\
351\end{array}$} & \multirow{2}{*}{$\begin{array}{c}\text { High-speed railway } \\
310 \\
\end{array}$} \\
\hline Kiev & Poltava & & & \\
\hline Poltava & Kharkiv & 150 & 140 & 130 \\
\hline \multicolumn{2}{|c|}{ Amount } & 487 & 491 & 440 \\
\hline Poltava & Dnepropetrovsk & 196 & 214 & 130 \\
\hline Dnepropetrovsk & Zaporozhye & 97 & 126 & 80 \\
\hline \multicolumn{2}{|c|}{ Amount } & 293 & 340 & 210 \\
\hline Dnepropetrovsk & Donetsk & 253 & 269 & 220 \\
\hline Donetsk & Lugansk & 148 & 152 & 140 \\
\hline Donetsk & Mariupol & 121 & 110 & 120 \\
\hline \multicolumn{2}{|c|}{ Amount } & 522 & 531 & 480 \\
\hline Kiev & Belaya Tserkov & 67 & 90 & 65 \\
\hline Belaya Tserkov & Nikolaev & 409 & 512 & 340 \\
\hline Nikolaev & Odessa & 120 & 242 & 120 \\
\hline Nikolaev & Kherson & 66 & 62 & 60 \\
\hline Kherson & Simferopol & 251 & 275 & 240 \\
\hline \multicolumn{2}{|c|}{ Amount } & 913 & 1181 & 825 \\
\hline Belaya Tserkov & Vinnitsa & 150 & 200 & 130 \\
\hline Vinnitsa & Khmelnitsky & 120 & 146 & 110 \\
\hline Khmelnitsky & Ternopil & 114 & 119 & 105 \\
\hline Ternopil & Lviv & 128 & 141 & 120 \\
\hline \multicolumn{2}{|c|}{ Amount } & 512 & 606 & 465 \\
\hline Dnepropetrovsk & Krivoy Rog & 151 & 165 & 150 \\
\hline Krivoy Rog & Nikolaev & 159 & 217 & 150 \\
\hline \multicolumn{2}{|c|}{ Amount } & 310 & 382 & 300 \\
\hline Zaporozhye & Melitopol & 113 & 115 & 110 \\
\hline Melitopol & Simferopol & 248 & 241 & 241 \\
\hline \multicolumn{2}{|c|}{ Amount } & 361 & 356 & 351 \\
\hline
\end{tabular}

Each scenario has a different impact on rolling stock, networking, infrastructure, and financial issues. These results are presented in the following tables.

Scenario 1: Ukrainian high-speed network with a track width of $1520 \mathrm{~mm}$. There is no compatibility with European high-speed lines. 
The total amount of fixed costs for research, approval of rolling stock, design of tracks and construction works is estimated at 100 million Euros. Typically, in Western Europe, the design of a new high-speed composition takes 3 to 5 years.

Scenario 2: Ukrainian high-speed network with a gauge of $1435 \mathrm{~mm}$. There is no compatibility with the traditional network of Ukrainian railways; there is no compatibility with high-speed networks of the CIS countries (in case they take a gauge of $1520 \mathrm{~mm}$ ) Minimum costs for adapting existing stations in comparison with the total costs for this project.

Scenario 3: Rolling stock, adapted for two types of track width. Designing a new type of rolling stock with an automatically variable width of wheel pairs $1435 / 1520 \mathrm{~mm}$. A more complex rolling stock design entails an increase in maintenance costs and a lengthy approval process for this solution. The total amount of fixed costs for the study and approval of the rolling stock system is estimated at 50 million Euros. Typically in Western Europe, the design of a new high-speed rolling stock takes 3 to 5 years.

Taking into account the presented information, the choice of track width for the Ukrainian high-speed network is more operational, financial and political, rather than a technical issue $[5,7,10]$.

The introduction of the high-speed railway network proposed for Ukraine should be carried out in stages. A program for the development of high-speed lines should be developed, in which priority should be given to the introduction of these lines. The following aspects should be analyzed in order to determine whether it is expedient to continue work on any component: financial profit, socio-economic aspects, environmental impact and political criteria. This study showed that the entire network from an economic point of view is appropriate. Therefore, further feasibility study of the project is recommended. Such a study is aimed at detailed development.

From the point of view of economic profitability, according to calculations of the company SYSTRA, the following sequence of construction of the high-speed railway, presented in Table 2, is proposed.

Table 2. Stages of construction of railways.

\begin{tabular}{|c|c|c|c|}
\hline Stages & Point of departure & Point of arrival & High-speed railway \\
\hline \multirow{4}{*}{ I } & Kiev & Poltava & 310 \\
\cline { 2 - 4 } & Poltava & Kharkiv & 130 \\
\cline { 2 - 4 } & Poltava & Dnepropetrovsk & 130 \\
\cline { 2 - 4 } & Amount & \multicolumn{2}{|c|}{5701} \\
\hline \multirow{4}{*}{ II } & Dnepropetrovsk & Donetsk & 220 \\
\cline { 2 - 4 } & Dnepropetrovsk & Zaporozhye & 80 \\
\cline { 2 - 4 } & Amount & \multicolumn{2}{|c|}{300} \\
\hline \multirow{4}{*}{ III } & Kiev & Belaya Tserkov & 65 \\
\cline { 2 - 4 } & Belaya Tserkov & Nikolaev & 340 \\
\cline { 2 - 4 } & Nikolaev & Odessa & 120 \\
\cline { 2 - 4 } & Amount & \multicolumn{2}{|c|}{525} \\
\hline \multirow{4}{*}{ IV } & Belaya Tserkov & Vinnitsa & 130 \\
\cline { 2 - 4 } & Vinnitsa & Khmelnitsky & 110 \\
\cline { 2 - 4 } & Khmelnitsky & Ternopil \\
\cline { 2 - 4 } & Ternopil & Lviv & 120 \\
\cline { 2 - 4 } & Amount & \multicolumn{2}{|c}{465} \\
\hline \multirow{2}{*}{ V } & Nikolaev & Kherson & 60 \\
\cline { 2 - 4 } & Kherson & Simferopol & 240 \\
\hline
\end{tabular}




\begin{tabular}{|c|c|c|c|}
\hline & Amount & \multicolumn{2}{|c|}{300} \\
\hline \multirow{3}{*}{ VI } & Dnepropetrovsk & Krivoy Rog & 150 \\
\cline { 2 - 4 } & Krivoy Rog & Nikolaev & 150 \\
\cline { 2 - 4 } & Amount & & \multicolumn{2}{|c|}{300} \\
\hline \multirow{3}{*}{ VII } & Zaporozhye & Melitopol & 110 \\
\cline { 2 - 4 } & Melitopol & Simferopol & 241 \\
\cline { 2 - 4 } & Amount & & \multicolumn{2}{|c|}{351} \\
\hline \multirow{3}{*}{ IIX } & Donetsk & Lugansk & 140 \\
\cline { 2 - 4 } & Donetsk & Mariupol & \multicolumn{2}{|c|}{260} \\
\cline { 2 - 4 } & Amount & \multicolumn{2}{|c|}{} \\
\hline
\end{tabular}

When operating the entire network, starting from 2035 - 2040, the network will be able to use about 130 million passengers annually or 356 thousand passengers daily. This amount of traffic means an annual passenger turnover of 54 billion pass-km [7].

About 34 different routes and 200 trains daily throughout the network will be put into operation. Thus, the entire network will be covered to meet demand.

Taking into account the recommendations of the company SYSTRA of Khargiprotrans JSC, a feasibility study of the high-speed railway Kiev-PoltavaKharkov was developed for the speed of passenger trains of $250 \mathrm{~km} / \mathrm{h}$. Khargiprotrans JSC has designed several options and the main indicators are given in Table 3.

Table 3. Key indicators of high-speed railroad options Kyiv - Poltava - Kharkov

\begin{tabular}{|c|c|c|c|c|}
\hline \multirow{2}{*}{ Options } & \multirow{2}{*}{ Units } & \multicolumn{3}{|c|}{ Variant } \\
\cline { 3 - 5 } & $\mathrm{km}$ & 463 & I & III \\
\hline Variant length & $\mathrm{km}$ & 440 & 404 & 457 \\
\hline Length of the new line & $\mathrm{km}$ & 23 & 50 & 507 \\
\hline $\begin{array}{c}\text { Length of the existing } \\
\text { railway }\end{array}$ & $\mathrm{mln} \cdot \mathrm{m}^{3}$ & 49,7 & 45,6 & 46,0 \\
\hline $\begin{array}{c}\text { Profile volume of } \\
\text { excavation works }\end{array}$ & hectare & 1760 & 1600 & 1650 \\
\hline Area of the right-of-way & & \multicolumn{3}{|c}{} \\
\hline
\end{tabular}

In order to evaluate this or that alternative, you must choose the optimality criterion. In modern conditions, the integral effect is taken as the criterion of optimality $E_{\text {int }}$, which is determined by the formula

$$
E_{\text {int }}=\sum\left(R_{t}-K_{t}\right) \eta_{t}
$$

where $T_{p}$ - settlement period, $R_{t}$ - result for the year, $K_{t}$ - outgoings for the year;

$\eta_{t}$ - the discount rate is determined by the formula

$$
\eta_{t}=\frac{1}{(1+E)^{t}}
$$

where $E$ - discount rate.

With the optimality criteria (1), a passive search method can be used to find the optimal variant, which is used with a small interval of uncertainty.

In the presence of a large number of possible options for finding the optimal solution, apply directional search. There are a lot of targeting methods, they have their drawbacks and advantages. 
For today, 10 high-speed trains "Intercity" of Korean production "Hyundai" and two trains of the company "Skoda" run in Ukraine. The maximum speed of these trains is $160 \mathrm{~km} / \mathrm{h},[5]$.

\section{Conclusions}

The introduction of the high-speed railway network proposed for Ukraine should be carried out in stages. A program for the development of high-speed lines should be developed, in which priority should be given to the introduction of these lines. As a result of the conducted research, it was established that the speed limit on the hauls was caused by the following main reasons: a) unsatisfactory condition or presence of defects in the earthen linen and artificial structures; b) insufficient capacity of the upper structure of the track; c) unfavorable conditions of the plan and profile.

For Ukraine, first of all, it is necessary to put into operation the fourth stage of construction, based on the analysis of the passenger traffic of Derzhstat, which will connect Lviv with Kiev.

In the considered direction, the roadbed and artificial structures are in satisfactory condition. The upper structure of the track has sufficient power. The effect of the profile on the speed of motion is compensated by the power of the locomotive.

Thus, the main reason for the restriction of the speed of the passenger trains on the runway is the conditions of the line plan. The line plan for this direction is relatively favorable, but nevertheless there are the following drawbacks: a) the presence of curves of small radii $(600-700 \mathrm{~m})$; b) insufficient length of straight inserts between the curves; c) insufficient elevation of the outer rail in the curved sections of the track; d) a large amount of elevation slopes due to insufficient length of transitional curves; e) location of turnouts in curved sections of the track; e) availability of stations on main routes; g) on the main tracks of large stations, shunting routes with human flows in one level often

\section{References}

1. Regulations on carrying out planned preventive repair and road works on the railways of Ukraine (Ministry Transport of Ukraine, 2004)

2. M. B. Kurhan, D. M. Kurhan, Theoretical basis for the introduction of high-speed trains in Ukraine, (DNUZT, Dnipro, 2016).

3. Korzhenevich I.P. Railway transport of Ukraine, 5, 79-82 (2015)

4. Guidance on the main issues of the arrangement and maintenance of the Railroad. (Transport of Ukraine, 2007)

5. A.A. Shevchenko. Conference materials 80th International Scientific and Technical Conference, 177, 112-113 (2018)

6. Vytautas Dzerkelis, Žilvinas Bazaras, Vaidas Lukoševičius. Transport, 30(2), 194 201 (2015)

7. Marijonas Bogdevičius, Rasa Žygienè, Stasys Dailydka, Vilius Bartulis, Viktor Skrickij, Saugirdas Pukalskas. Transport, 30(2), 217-232 (2015)

8. Paola Carolina Bueno Cadena, José Manuel Vassallo Magro. Transport, 30(3), 298-306 (2015) 
9. G.M. Kirpa, Integration of Ukraine's railway transport into the European transport system, (DNUZT, 2004)

10. M.B. Kurhan, D.M. Kurhan, Science and Transport Progress. Bulletin of Dnipropetrovsk National University of Railway Transport, 6(72), 40-48 (2017) 